\title{
Constipation Is Related to Small Bowel Disturbance Rather Than Colonic Enlargement in Acquired Chagasic Megacolon
}

\author{
Mauro Bafutto ${ }^{\mathrm{a}, \mathrm{b}}$, Alejandro Ostermayer Luquetti ${ }^{\mathrm{b}}$, Salustiano Gabriel Neto ${ }^{\mathrm{b}, \mathrm{c}}$, \\ Felix Andre Sanches Penhavel ${ }^{\mathrm{b}, \mathrm{c}}$, Enio Chaves Oliveira ${ }^{\mathrm{b}, \mathrm{c}, \mathrm{d}}$
}

\begin{abstract}
Background: Constipation is the main symptom of acquired chagasic megacolon. However, a number of patients with Chagas disease without colon involvement also have the same complain. This study evaluated the role of small bowel in constipated patients with Chagas disease with and without megacolon.

Methods: Orocecal transit time (OCTT) and oral glucose tolerance test (OGTT) in constipated non-chagasic and chagasic patients with and without megacolon were performed. One hundred fifteen patients were included in this study and were divided into two groups based on the presence or absence of constipation, which is defined as at least 7 days without bowel movements for more than 1 year. These two groups were further divided into three subgroups based on the serology test results for Trypanosoma cruzi and the presence and absence of megacolon on barium enema. All patients were subjected to OCTT and OGTT.
\end{abstract}

Results: Among 70 constipated patients, $64.3 \%$ had OCTT longer than $120 \mathrm{~min}$, higher than the non-constipated patients $(31.1 \%, \mathrm{P}<$ 0.000 ). The proportion of patients within the three subgroups in the non-constipated group was not different from each other $(\mathrm{P}=0.345)$. Among the constipated subgroup, $94.44 \%$ of the chagasic megacolon subgroup had OCTT longer than 120 min, higher than the other two subgroups $(\mathrm{P}=0.005)$. Chagas patients with constipation, without or without megacolon, showed higher blood glucose levels at 30, 60, and 90 min after oral ingestion of $70 \mathrm{~g}$ glucose than normal subjects with or without constipation.

Conclusions: Constipated, either non-chagasic or chagasic, patients have a prolonged OCTT. This result suggests that slow small bowel transit may be a significant factor for constipation.

Manuscript submitted May 28, 2017, accepted July 3, 2017

${ }^{a}$ Gastroenterology Division, Internal Medicine Department, School of Medicine, Universidade Federal de Goias, Goiania, Brazil

bNucleo de Estudo da Doenca de Chagas, Hospital das Clinicas, Universidade Federal de Goias, Brazil

'Digestive Surgery Division, Surgery Department, School of Medicine, Universidade Federal de Goias, Goiania, Brazil

${ }^{\mathrm{d} C}$ Corresponding Author: Enio C. Oliveira, Rua Jequitiba Q-27A L-28 Aldeia do Vale, 74680-245 Goiania, Goias, Brazil. Email: eco1.br@gmail.com

doi: https://doi.org/10.14740/gr872w
Keywords: Megacolon; Constipation; Small bowel; Enteric nervous system

\section{Introduction}

Constipation may be considered as a symptom, not always isolated, which may accompany several functional disorders and organic diseases, digestive or extra-digestive $[1,2]$.

Constipation is the main symptom of acquired megacolon due to Chagas disease ranging from days to months, for many years [3]. Chagas disease is endemic in Latin America [4] and may present different clinical forms. In Central Brazil, the digestive involvement is common and characterized by mega syndromes: megacolon and megaesophagus [3]. Megaformations are caused by neuron cells destruction of the enteric nervous system all along the digestive tube by the protozoan parasite Trypanosoma cruzi [5].

Nevertheless, constipation and megacolon are not associated in all cases, as described recently [6, 7], with a significant number of patients with megacolon and normal bowel movements. These observations led us to search for other causes of constipation [8] in those infected but without colonic dilatation, as well as explanations for those with megacolon but no constipation.

Considering that constipation is an important but not universal clinical finding in patients with chagasic megacolon, and uneven destruction of submucous and myenteric plexus of enteric nervous [9] in the digestive tube in Chagas disease, this study aimed at the investigation of the small bowel motility and its absorption capacity.

Considering that constipation is also a common complain in non-chagasic population $[10,11]$ and that colonic dilatation could be a coincidental finding, it was thought that small bowel could have a role in the mechanism of constipation. The purpose of this study was to evaluate the orocecal transit time (OCTT) and oral glucose tolerance test (OGTT) in chagasic patients with and without megacolon, with constipation or not, and non-chagasic controls.

\section{Patients and Methods}

This study was approved by the Ethics Committee of the Clinical Hospital of the Federal University of Goias (CEPMHA/HC/ 
Table 1. Clinical Groups and Demographic Data

\begin{tabular}{llllllll}
\hline \multirow{2}{*}{ Groups } & Chagas disease & Barium enema & N & & \multicolumn{2}{c}{ Constipation } & Mean age (years) \\
& & & Days & Years & & Sex ratio (M/F) \\
N & No & ND & 9 & No & & 47 & $3: 6$ \\
CN & No & Normal & 38 & $7-30$ & $1-40$ & 44 & $3: 35$ \\
ChN & Yes & Normal & 20 & No & & 65 & $8: 12$ \\
CCh & Yes & Normal & 14 & $7-60$ & $3-30$ & 61 & $4: 10$ \\
ChMc & Yes & Megacolon & 16 & No & & 64 & $7: 9$ \\
CChMc & Yes & Megacolon & 18 & $7-60$ & $3-30$ & 59 & $8: 8$ \\
\hline
\end{tabular}

ND: not done.

UFG 006/2011). All patients signed an informed consent form. Included Chagas patients in this study were adults aged between 21 and 80 years. All Chagas patients tested positive for T. cruzi infection by one of the methods: ELISA, hemaglutination and indirect immunofluorescence. Controls had negative serology for T. cruzi infection. Constipation is defined as seven or more days without bowel movements. All chagasic and constipated patients had colonic evaluation with barium enema. Non-chagasic patients with normal bowel movements (control volunteers) were not subjected to barium enema.

Exclusion criteria include use of medications that may modify the transit or absorption of the small intestine, previous gastrointestinal surgery, the presence of advanced megaesophagus and severe dysphagia, diabetes mellitus, and neurological disorders and hypothyroidism.

Patients were divided into two groups: non-constipated and constipated. Each group was splited in three subgroups: non-chagasic, chagasic with megacolon and chagasic without megacolon, as follows: non-constipated - normal $(\mathrm{N})$; nonconstipated - chagasic without megacolon $(\mathrm{ChN})$; non-constipated - chagasic with megacolon (ChMc); constipated - normal $(\mathrm{CN})$; constipated - chagasic without megacolon (CCh); and constipated - chagasic with megacolon (CChMc).

Small bowel motility and absorption capacity were evaluated by OCTT and OGTT, respectively. More specifically, OCTT, an expired $\mathrm{H}_{2}$ breath test, was performed with an Hydrahale $^{\circledR}$ (Micro Medical Limited, Rochester, Kent, UK) device. After a basal measure $10 \mathrm{~g}$ of lactulone was administered to patients, following measures were taken after 30, 40, 50, 60, $70,80,90,100,110,120,140,160,180$ and $200 \mathrm{~min}$. Values more than 20 parts per million ( $\mathrm{ppm}$ ) were considered as colonic lactulose metabolism. A delayed OCTT was considered after 120 min without increase in $\mathrm{H}_{2}$ exhaled and patients were classified in normal (up to $120 \mathrm{~min}$ ) and delayed OCTT (more than $120 \mathrm{~min}$ ) [12]. OGTT was performed as follows: after 12-h fast, peripheral blood samples were drawn just before oral ingestion of $70 \mathrm{~g}$ of glucose and then at 30,60, 90 and $120 \mathrm{~min}$ after oral ingestion of $70 \mathrm{~g}$ of glucose and used for the determination of blood glucose.

\section{Statistical analysis}

Comparative analysis among the six groups was made with non-parametric Kruskal-Wallis test. Statistical significance was admitted for $\mathrm{P}<0.05$.

\section{Results}

A total of 115 patients, 33 men and 82 women with age ranging from 21 to 80 years, were included and divided in the clinical groups as seen in Table 1. Constipation in chagasic patients varied from 7 to 60 days during 1 - 30 years while those constipated controls reported 7 - 30 days of constipation for 1 - 40 years.

Among 70 constipated patients, 64.3\% had OCTT longer than $120 \mathrm{~min}$, higher than the non-constipated patients $(31.1 \%$, $\mathrm{P}<0.000)$. The proportion of patients within the three subgroups in the non-constipated group was not different from each other $(P=0.345)$. Among the constipated subgroup, $94.44 \%$ of the chagasic megacolon subgroup had OCTT longer than $120 \mathrm{~min}$, higher than the other two subgroups $(\mathrm{P}=0.005)$. The mean of OCTT is higher in the chagasic megacolon subgroup compared to other groups $(\mathrm{P}=0.001)$ (Table 2$)$.

Chagas patients with constipation, without or without megacolon, showed higher blood glucose levels at 30,60, and $90 \mathrm{~min}$ after oral ingestion of $70 \mathrm{~g}$ glucose than normal subjects with or without constipation (Table 3).

\section{Discussion}

This paper shows that a small bowel disturbance is found in constipated patients despite the presence of colon enlargement in patients with Chagas disease. No difference was found in the three subgroups of non-constipated patients concerning OCTT. To date, this is the first report about the involvement of small bowel in the constipation related to acquired megacolon. Our data show clearly that constipation is related to a delayed OCTT and not related to megacolon. Patients with constipation and megacolon may represent the most affected group in terms of injury of the enteric nervous system and megacolon may be a clinical marker of this severity.

Our study revealed small bowel motility abnormalities in constipated chagasic patients with megacolon compared to chagasic patients with megacolon but without constipation. The implication of these findings to pathophysiology of 
Table 2. Results of Orocecal Transit Time in Clinical Groups

\begin{tabular}{|c|c|c|c|c|c|c|}
\hline \multirow{2}{*}{ Groups } & \multirow{2}{*}{ Subgroups } & \multirow{2}{*}{$\mathbf{n}$} & \multirow{2}{*}{ Mean (SD) } & \multirow{2}{*}{$95 \%$ CI } & \multicolumn{2}{|c|}{ OCTT (min) } \\
\hline & & & & & $<120$, n $(\%)$ & $>120$, n $(\%)$ \\
\hline \multirow[t]{3}{*}{ Non-constipated $^{\mathrm{a}}$} & $\mathrm{N}^{\mathrm{b}}$ & 9 & $87.0(47.9)$ & $52.8-121.2$ & $8(88.89)$ & $1(11.11)$ \\
\hline & $\mathrm{ChN}^{\mathrm{b}}$ & 20 & $109.0(54.6)$ & $83.5-134.5$ & $13(65.0)$ & $7(35.0)$ \\
\hline & $\mathrm{ChMc}^{\mathrm{b}}$ & 16 & $110.0(63.8)$ & $76.0-144.0$ & $10(66.67)$ & $6(33.33)$ \\
\hline \multirow[t]{2}{*}{ Constipated $^{\mathrm{a}}$} & $\mathrm{CN}^{\mathrm{c}}$ & 38 & $119.8(55.4)$ & $102.5-137.0$ & $19(50.0)$ & $19(50.0)$ \\
\hline & $\mathrm{CCh}^{\mathrm{c}}$ & 14 & $93.3(50.5)$ & $65.4-121.3$ & $5(35.72)$ & $9(64.28)$ \\
\hline Total & & 115 & $119.0(58.8)$ & $108.5-129.6$ & 56 & 59 \\
\hline
\end{tabular}

SD: standard deviation; Cl: confidence interval; OCTT: orocecal transit time. ${ }^{\mathrm{P}} \mathrm{P}<0.000$; ${ }^{\mathrm{b}} \mathrm{P}=0.345 ;{ }^{\mathrm{c} P}=0.005$; ${ }^{\mathrm{d}} \mathrm{P}=0.001$ (Kruskal-Wallis test).

Table 3. Oral Glucose Tolerance Test in Clinical Groups

\begin{tabular}{|c|c|c|c|c|c|c|c|}
\hline \multirow{2}{*}{ Time (min) } & \multirow{2}{*}{ Groups } & \multirow{2}{*}{$\mathbf{n}$} & \multirow{2}{*}{ Mean } & \multirow{2}{*}{ SD } & \multicolumn{2}{|c|}{$95 \%$ CI } & \multirow{2}{*}{$\mathbf{P}$} \\
\hline & & & & & Lower & Upper & \\
\hline \multirow[t]{6}{*}{0} & $\mathrm{~N}$ & 9 & 87.6 & 11.2 & 79.6 & 95.6 & \multirow[t]{6}{*}{0.396} \\
\hline & $\mathrm{ChN}$ & 20 & 86.9 & 9.4 & 82.5 & 91.3 & \\
\hline & $\mathrm{ChMc}$ & 16 & 87.7 & 8.9 & 82.9 & 92.4 & \\
\hline & $\mathrm{CN}$ & 38 & 86.7 & 10.0 & 83.6 & 89.9 & \\
\hline & $\mathrm{CCh}$ & 14 & 92.7 & 9.0 & 87.7 & 97.7 & \\
\hline & CChMc & 18 & 88.6 & 9.4 & 84.1 & 93.2 & \\
\hline \multirow[t]{6}{*}{$30 *$} & $\mathrm{~N}$ & 9 & 127.5 & 27.0 & 108.2 & 146.8 & \multirow[t]{6}{*}{0.003} \\
\hline & $\mathrm{ChN}$ & 20 & 142.6 & 32.0 & 127.6 & 157.5 & \\
\hline & $\mathrm{ChMc}$ & 16 & 155.5 & 39.8 & 134.3 & 176.7 & \\
\hline & $\mathrm{CN}$ & 14 & 131.9 & 26.8 & 123.6 & 140.3 & \\
\hline & $\mathrm{CCh}$ & 38 & 163.3 & 34.4 & 144.3 & 182.4 & \\
\hline & CChMc & 18 & 157.2 & 29.9 & 142.8 & 171.6 & \\
\hline \multirow[t]{6}{*}{$60 * *$} & $\mathrm{~N}$ & 9 & 116.0 & 46.8 & 82.5 & 149.5 & \multirow[t]{6}{*}{0.005} \\
\hline & $\mathrm{ChN}$ & 20 & 133.3 & 40.3 & 114.5 & 152.1 & \\
\hline & $\mathrm{ChMc}$ & 16 & 152.4 & 49.2 & 126.2 & 178.6 & \\
\hline & $\mathrm{CN}$ & 38 & 122.1 & 39.6 & 109.8 & 134.4 & \\
\hline & $\mathrm{CCh}$ & 14 & 170.5 & 61.0 & 136.7 & 204.2 & \\
\hline & CChMc & 18 & 145.2 & 37.3 & 127.2 & 163.2 & \\
\hline \multirow[t]{6}{*}{$90 * * *$} & $\mathrm{~N}$ & 9 & 101.0 & 32.7 & 77.6 & 124.4 & \multirow[t]{6}{*}{0.001} \\
\hline & $\mathrm{ChN}$ & 20 & 119.0 & 36.8 & 101.8 & 136.2 & \\
\hline & $\mathrm{ChMc}$ & 16 & 135.7 & 48.0 & 110.1 & 161.3 & \\
\hline & $\mathrm{CN}$ & 38 & 110.6 & 34.2 & 100.0 & 121.3 & \\
\hline & $\mathrm{CCh}$ & 14 & 149.5 & 55.6 & 118.7 & 180.3 & \\
\hline & $\mathrm{CChMc}$ & 18 & 144.2 & 37.7 & 126.0 & 162.4 & \\
\hline \multirow[t]{6}{*}{120} & $\mathrm{~N}$ & 9 & 92.9 & 24.3 & 75.5 & 110.3 & \multirow[t]{6}{*}{0.400} \\
\hline & $\mathrm{ChN}$ & 20 & 102.5 & 30.8 & 88.1 & 116.9 & \\
\hline & $\mathrm{ChMc}$ & 16 & 116.2 & 40.5 & 94.6 & 137.7 & \\
\hline & $\mathrm{CN}$ & 14 & 98.3 & 28.0 & 89.5 & 107.0 & \\
\hline & $\mathrm{CCh}$ & 38 & 122.3 & 55.6 & 91.5 & 153.1 & \\
\hline & $\mathrm{CChMc}$ & 18 & 114.8 & 37.5 & 96.7 & 132.9 & \\
\hline
\end{tabular}

Kruskal-Wallis test; min: minute. ${ }^{*} \mathrm{~N}$ and $\mathrm{CN}$ compared to $\mathrm{ChMc}, \mathrm{CCh}, \mathrm{CChMc}$; ${ }^{*} \mathrm{~N}$ and $\mathrm{CN}$ compared to $\mathrm{ChMc}, \mathrm{CCh}$, CChMc; ${ }^{* * *} \mathrm{~N}$ and $\mathrm{CN}$ compared to $\mathrm{ChMc}, \mathrm{CCh}, \mathrm{CChMc}$ and $\mathrm{ChN}$ compared to CChMc. 
acquired megacolon is significant because the enlargement alone was believed to be responsible for constipation [3]. Our current findings are consistent with two previous studies that suggested that constipation may not necessarily overlap with megacolon. For example, Ximenes et al (1984) [6] found 20 patients with megacolon and seven out of them had normal bowel movements and Rassi et al (1989) [7] reported that among 232 patients with cardiopathy, 49 had megacolon and $28(57 \%)$ of them did not have constipation. Probably constipation and dilatation may be related to different types of injury to submucous and myenteric plexus, respectively [13].

It is well known that chagasic patients have a destruction of neuron cells of the enteric nervous system and that this occurs from the esophagus till the anus [14]. Probably the affected small bowel from chagasic patients may share some similarities to constipated non-chagasic patients. In the chagasic patients, it is known that destruction of neuron cells is caused by $T$. cruzi infection. However, the real mechanism of destruction is not complete understood $[9,14]$.

The mechanism of constipation in Chagas patients remains unclear, although it is well known that chagasic patients demonstrate loss of neuron cells of their enteric nervous system as a result of neural destruction which occurs from the esophagus to the anus. Whether small bowel abnormalities play a role in constipation in chagasic patients is not well known. Previous studies in non-chagasic patients with colonic inertia did show changes in peristalsis of the jejunum [15], decrease in interstitial cells of Cajal $[16,17]$, an increased number of mast cells [18], alteration of enterochromaffin cells [19, 20], abnormalities in terminal ileum with decreased number of enteric glial cells and interstitial cells of Cajal [21]. In the colon specimens from chagasic patients with megacolon, a loss of interstitial cells of Cajal was reported [22, 23]. In addition, high levels of substance $\mathrm{P}$ and low levels of NK1 receptor, evidence of VIP and NOS neuron destruction, were observed in chagasic patients $[24,25]$. These previous studies suggested that similar neuropathic events may occur in the small bowel in chagasic patients and potentially contribute to constipation. However, studies on small intestine in chagasic patients are scarce. One study revealed that a variable degree of denervation of the small bowel occurred in approximately $50 \%$ of cases [26]. Other studies also examined radiographically, manometrically, and biochemically small bowel function including motility and absorption of monosaccharides [27].

To date, we are not aware of a study that measures OCTT in chagasic patients with constipation. A study performed on measurements of orocecal time through the exhaled $\mathrm{H}_{2}$ and scintillography in patients with Chagas disease, demonstrated a combination of increased gastric emptying and delayed transit in the distal portions of the small intestine [28]; however, no studies have been conducted related to constipation. In this study, the test of exhaled $\mathrm{H}_{2}$ was used for measurement of OCTT. We observed an increase of this time with a statistically significant difference between the group of chagasic patients with megacolon and constipation compared to all other groups. This observation that constipated chagasic patients with megacolon have small bowel motility abnormality as measured by OCTT strongly suggests that megacolon is not the only factor responsible for Chagas constipation. In constipated chagasic patients without megacolon, examination of the small bowel function by OCTT may provide clue for the etiology of constipation.

Meneghelli (2004) reported that chagasic patients may have an increased absorption of glucose by the small bowel [27]. Our results reinforce this observation and our data showed an OGTT in constipated chagasic similar to diabetic patients. To date, we are not aware of a study on measurement of glycemic curve in patients with Chagas disease with constipation. To demonstrate that disturbance was in the absorption process, Meneghelli et al (1969) reported no difference response to intravenous challenge of glucose load response in chagasic and controls [29]. Alteration of intestinal absorption of glucose was observed in Chagas patients with curves peaking at $30 \mathrm{~min}$ after ingestion, returning to baseline after $120 \mathrm{~min}$. It is believed that this abnormality in glucose uptake is related to parasympathetic denervation of small intestine in Chagas disease [27] but no study has been conducted related to constipation.

The mechanism of constipation in chagasic patients may involve alterations in absorption, motility, and anatomy. An increased glucose absorption followed by absorption of water may lead to dehydration of feces which may potentially further slow down its transit in the small bowel in addition to the slow motility as a result of neuropathic events. The interplaying of small bowel motility and increased small bowel glucose absorption after oral glucose ingestion in constipated chagasic patients with or without megacolon needs additional studies.

\section{Funding Support}

None.

\section{Conflicts of Interest}

The authors declare that they have no conflicts of interest.

\section{References}

1. Costilla VC, Foxx-Orenstein AE. Constipation: understanding mechanisms and management. Clin Geriatr Med. 2014;30(1):107-115.

2. Alame AM, Bahna H. Evaluation of constipation. Clin Colon Rectal Surg. 2012;25(1):5-11.

3. Rezende JM, Luquetti AO. Chagasic megaviscera. In: Chagas disease and the nervous system. Pan American Health Organization Scientific Publication 547. Washington. 1984; p. 160-183.

4. Schmunis G. American trypanosomiasis as a public health problem. In: Chagas disease and the nervous system. Pan American Health Organization Scientific Publication 547. Washington. 1984; p. 3-29.

5. Brener Z. The pathogenesis of Chagas disease: an overview of current theories. In: Chagas disease and the nervous system. Pan American Health Organization Scientific Publication 547. Washington. 1984; p. 30-46. 
6. Ximenes CA, Rezende JM, Moreira H, Vaz MGM. Tecnica simplificada para o diagnostico radiologico do megacolon chagasico. Rev Soc Bras Med Trop. 1984;17:23.

7. Rassi A, Rezende JM, Moreira H, Ximenes CA, Luquetti AO, Lousa L, Ferriolli Filho F. Associacao de cardipatia, megesofago e megacolon na fase cronica da doenca de Chagas. Rev Soc Bras Med Trop. 1986;17:29.

8. Longstreth GF, Thompson WG, Chey WD, Houghton LA, Mearin F, Spiller RC. Functional bowel disorders. Gastroenterology. 2006;130(5):1480-1491.

9. Lazzari JO. Autonomic nervous system alterations in Chagas disease: review of the literature. In: Chagas disease and the nervous system. Pan American Health Organization Scientific Publication 547. Washington. 1984; p. 72-98.

10. Higgins PD, Johanson JF. Epidemiology of constipation in North America: a systematic review. Am J Gastroenterol. 2004;99(4):750-759.

11. Johanson JF, Kralstein J. Chronic constipation: a survey of the patient perspective. Aliment Pharmacol Ther. 2007;25(5):599-608.

12. La Brooy SJ, Male PJ, Beavis AK, Misiewicz JJ. Assessment of the reproducibility of the lactulose $\mathrm{H} 2$ breath test as a measure of mouth to caecum transit time. Gut. 1983;24(10):893-896.

13. Oliveira EC, Menezes JG, Cardoso VK, Luquetti AO, Gabriel Neto S, Garcia SB. The Relationship between megacolon and constipation in Chagas' disease. Neurogastroenterol Motil. 2009;21(suppl 1):5.

14. Brener Z. The pathogenesis of Chagas disease: an overview of current theories. In: Chagas disease and the nervous system. Pan American Health Organization Scientific Publication 547. Washington. 1994; p. 30-46.

15. Scott SM, Picon L, Knowles CH, Fourquet F, Yazaki E, Williams NS, Lunniss PJ, et al. Automated quantitative analysis of nocturnal jejunal motor activity identifies abnormalities in individuals and subgroups of patients with slow transit constipation. Am J Gastroenterol. 2003;98(5):1123-1134.

16. Lyford GL, He CL, Soffer E, Hull TL, Strong SA, Senagore AJ, Burgart LJ, et al. Pan-colonic decrease in interstitial cells of Cajal in patients with slow transit constipation. Gut. 2002;51(4):496-501.

17. Shafik A, Shafik AA, El-Sibai O, Shafik IA. Interstitial cells of cajal in patients with constipation due to total colonic inertia. J Invest Surg. 2006;19(3):147-153.

18. Bassotti G, Villanacci V, Nascimbeni R, Cadei M, Manenti S, Sabatino G, Maurer CA, et al. Colonic mast cells in controls and slow transit constipation patients. Aliment Pharmacol Ther. 2011;34(1):92-99.

19. Baig MK, Zhao RH, Woodhouse SL, Abramson S, Weiss JJ, Singh EG, Nogueras JJ, et al. Variability in serotonin and enterochromaffin cells in patients with colonic inertia and idiopathic diarrhoea as compared to normal controls. Colorectal Dis. 2002;4(5):348-354.

20. Zhao R, Baig MK, Wexner SD, Chen W, Singh JJ, Nogueras JJ, Woodhouse S. Enterochromaffin and serotonin cells are abnormal for patients with colonic inertia. Dis Colon Rectum. 2000;43(6):858-863.

21. Bassotti G, Villanacci V, Cathomas G, Maurer CA, Fisogni S, Cadei M, Baron L, et al. Enteric neuropathology of the terminal ileum in patients with intractable slow-transit constipation. Hum Pathol. 2006;37(10):1252-1258.

22. Adad SJ, Silva GB, Jammal AA. The significantly reduced number of interstitial cells of Cajal in chagasic megacolon $(\mathrm{CM})$ patients might contribute to the pathophysiology of CM. Virchows Arch. 2012;461(4):385-392.

23. Hagger R, Finlayson C, Kahn F, De Oliveira R, Chimelli L, Kumar D. A deficiency of interstitial cells of Cajal in Chagasic megacolon. J Auton Nerv Syst. 2000;80(12):108-111.

24. da Silveira AB, Freitas MA, de Oliveira EC, Neto SG, Luquetti AO, Furness JB, Correa-Oliveira R, et al. Substance $\mathrm{P}$ and NK1 receptor expression in the enteric nervous system is related to the development of chagasic megacolon. Trans R Soc Trop Med Hyg. 2008;102(11):1154-1156.

25. Moreira MD, Brehmer A, de Oliveira EC, Neto SG, Luquetti AO, Bueno LL, Fujiwara RT, et al. Regenerative process evaluation of neuronal subclasses in chagasic patients with megacolon. Hum Immunol. 2013;74(2):181188.

26. Tafuri WL, Brener Z. [Lesions of the autonomic nervous system of the white mouse in the chronic phase of experimental trypanosomiasis cruzi]. Rev Inst Med Trop Sao Paulo. 1966;8(4):177-183.

27. Meneghelli UG. Chagasic enteropathy. Rev Soc Bras Med Trop. 2004;37(3):252-260.

28. Troncon LE, Oliveira RB, Romanello LM, Rosa-e-Silva L, Pinto MC, Iazigi N. Abnormal progression of a liquid meal through the stomach and small intestine in patients with Chagas' disease. Dig Dis Sci. 1993;38(8):15111517.

29. Meneghelli UG, Reis LC, Vichi FL, Lima Filho EC. [Metabolism of carbohydrates in Chagas' disease. IV. Intravenous glucose tolerance and tolbutamide tests]. Rev Paul Med. 1969;75(5):281-288. 